\title{
Cardiac sympathetic denervation for conventional treatment refractory arrhythmias
}

\section{Denervación simpática cardíaca en arritmias refractarias al tratamiento convencional}

\author{
Mauricio Velásquez¹, Liliana Fernández², Carl S. Leib ${ }^{3 *}$, Viviana Orozco ${ }^{3}$, Fernando Pava4 \\ and Pablo Perafan ${ }^{4}$
}

${ }^{1}$ Thoracic Surgery, Biomedical Research in Thorax; ${ }^{2}$ Internal Medicine, Pneumology, Biomedical Research in Thorax; ${ }^{3}$ Clinical Research Center, Biomedical Research in Thorax; ${ }^{4}$ Internal Medicine, Cardiology, Electrophysiology, Fundación Valle del Lili, Faculty of Health Sciences. Universidad ICESI, Cali, Colombia.

\begin{abstract}
Objective: Cardiac sympathetic denervation (CSD) using video-assisted thoracoscopy is a therapeutic alternative for cardiac arrhythmias refractory to conventional treatment in patients with ventricular structural heart disease, mainly due to ischemia, and in patients with hereditary conditions associated with sudden death such as long QT syndrome. In general, it is performed in cases with recurrent episodes of ventricular tachycardia or electrical storm, in spite of conventional treatment. The objective of this study is to show the experience of this institution with $\mathrm{DSCl}$ in refractory patients to conventional management and the results derived from its application. Methods: This was an observational retrospective study. The records of patients with a history of ventricular arrhythmias treated in our center with pharmacological treatment, catheter ablation, or implantation of an implantable cardioverter-defibrillator (ICD), who underwent video-assisted CSD were analyzed and described. Results: A total of six patients were included in the study. Patients with structural heart disease were the most frequent, median age was 56 \pm 16 years; $67 \%$ were male. The procedure evolved without complications in any of the patients and an overall significant improvement was observed. A 24-month follow-up was conducted; two patients had recurrence episodes presenting as slow ventricular tachycardia without severe symptoms and a third patient presented an episode of ventricular fibrillation aborted by the ICD. Conclusion: Video-assisted CSD should be considered as a treatment option for patients with potentially dangerous arrhythmias that do not respond to conventional treatment, especially in recurrent ventricular tachycardia.
\end{abstract}

Key words: Sympathectomy. Video-assisted thoracoscopy. Ventricular tachycardia. Structural heart disease. Long QT syndrome. Colombia.

\section{Resumen}

Objetivo: La denervación simpática cardiaca izquierda (DSCl) por toracoscopia se ha convertido en una alternativa terapéutica para el manejo de arritmias cardíacas refractarias al tratamiento convencional en pacientes con cardiopatía estructural, principalmente isquémicos, y enfermedades hereditarias asociadas con muerte súbita como el síndrome de QT largo. Generalmente se realiza en quienes manifiestan episodios recurrentes de arritmias ventriculares o incluso tormenta eléctrica a

\section{Correspondence:}

${ }^{*}$ Carl Sebastian Leib

Avenida Simón Bolívar, Cra 98, No. 18-49 Date of reception: 17-01-2018

Santiago de Cali, Colombia

E-mail: leib.sebastian@gmail.com
Available online: 02-10-2019

Date of acceptance: $28-11-2018$

DOI: 10.24875/ACM.M19000052
Arch Cardiol Mex. 2019;89(3):211-215

www.archivoscardiologia.com

1405-9940 @ 2018 Instituto Nacional de Cardiología Ignacio Chávez. Published by Permanyer México. This is an open access article under the CC BY-NC-ND license (http://creativecommons.org/licenses/by-nc-nd/4.0/). 
pesar del tratamiento convencional. El objetivo de este estudio es mostrar la experiencia de esta institución con la DSCl en pacientes refractarios al manejo convencional y los resultados derivados de su aplicación. Métodos: Se revisaron los registros de 6 pacientes con antecedente de arritmias ventriculares tratados previamente con medicamentos y en algunos casos con ablación con catéter y la mayoría con desfibrilador automático implantable, que fueron llevados DSCI por toracoscopia video-asistida (VATS). Resultados: La principal enfermedad de base fue la cardiopatía estructural, la indicación más prevalente fue tormenta arrítmica incontrolable, la edad promedio fue de $56 \pm 16$ años, el 67\% de los individuos fueron hombres. Este procedimiento no mostró complicaciones en ninguno de los pacientes y se encontró mejoría sintomática en todos los casos. Se realizó seguimiento por 24 meses; dos pacientes tuvieron recurrencias por taquicardia ventricular lenta sin síntomas severos y uno por fibrilación ventricular. Conclusion: La DSCI por VATS debe considerarse como opción terapéutica para pacientes con arritmias de difícil manejo.

Palabras clave: Simpatectomía. Toracoscopia video-asistida. Taquicardia ventricular. Síndrome de QT largo. Cardiopatía estructural. Colombia.

\section{Introduction}

Sudden cardiac death is defined as an unexpected natural death derived from a cardiac cause within a short time from the onset of symptoms, generally within $1 \mathrm{~h}$. In the majority of cases, this outcome is preceded by ventricular tachycardia ${ }^{1}$. Abnormal rhythms can be derived from genetic defects such as congenital long QT syndrome (LQTS) or due to structural heart disease secondary to myocardial ischemia, among others. In patients with ischemia, the affected tissue becomes highly arrhythmogenic due to cellular remodeling and the heterogeneity of the sympathetic innervations in the heart ${ }^{2}$.

The first line of therapy is pharmacological treatment with adrenergic beta-blockers, but recent studies have found that in patients with polymorphic ventricular tachycardia, up to $69 \%$ have recurrent cardiac events in spite of adequate management. In these refractory cases and patients with high risk of sudden death, an implantable cardioverter-defibrillator (ICD) has shown to be an effective therapy to prevent fatal outcomes ${ }^{3}$. ICDs are devices that are not exempt from complications such as inappropriate discharges with associated morbidity, mortality, and decreased the quality of life. As a result, ventricular arrhythmias (VAs) comprise a challenging condition regarding control and management, especially in recurrent or refractory cases.

The standard of care for patients with recurrent ventricular tachycardia or after the stabilization of a ventricular fibrillation is the use of antiarrhythmic drugs, the placing of an ICD, and, subsequently, catheter ablation; but only in selected patients and centers. In spite of advances in ablation technology, there is still a group of patients who do not respond to the aforementioned therapeutic approach ${ }^{4}$. The left cardiac sympathetic denervation (LCSD) or sympathectomy is a management option for patients with refractory arrhythmias taking into consideration the already demonstrated influence of the sympathetic nervous system in the genesis of the cardiac electrical instability. Sympathetic stimulation induces variations in the repolarization process predisposing the patient to ventricular fibrillation ${ }^{5}$. A higher sympathetic activity has been associated with patients presenting with ventricular tachyarrhythmia ${ }^{6}$. This study aims to present our experience with patients with refractory VA despite prior treatment attempts with antiarrhythmics and catheter ablation, taken to video-assisted thoracoscopic (VAT)-LCSD in a high-complexity care center in Latin America.

\section{Methods}

The surgical procedure was performed with general anesthesia in all the patients. Double lumen intubation was carried out to isolate the left lung; a videoscopic transthoracic left-sided approach was implemented in every case, due to thorough technique knowledge. A cervical approach is also possible, but it was not performed due to a higher risk of stellate ganglion lesion and a subsequent Horner's syndrome development. The left-sided ganglia were identified through the pleura. Electrocautery dissection of the thoracic sympathetic chain from T1 to T4 was executed and cut with endoscopic scissors, immediately underneath the stellate ganglion to avoid complications due to thermal dispersion. Then, the electrocautery was used to transect the sympathetic chain from T2 to T4. The dissected materials were removed and sent to pathology. Finally, the air was evacuated with a water seal chamber to avoid the use of a chest tube. All patients were monitored in the intensive care unit after the procedure. No complications were reported; the whole group of patients had significant improvement postoperatively. 
This study was performed with previous protocol approval by the institutional ethics committee (Comité de Ética Médica Institucional) at the Fundación Valle del Lili in Cali, Colombia. The records of six patients with a history of refractory VA were reviewed retrospectively. Patients who experienced no improvement in pharmacological treatment, implantable devices, or catheter ablation therapy were included in the study. Qualitative variables were resumed as percentages. To determine the behavior and the distribution of the numerical variables, we used the Shapiro-Wilk test. All analyses were performed using the statistical package STATA $^{\circledR}$ (StataCorp, 2011, Stata 12 Base Reference Manual, College Station, TX: Stata Press).

\section{Results}

In the period between January 2011 and December 2015, six patients were taken to VAT-LCSD at the Fundación Valle del Lili in Cali, Colombia; due to conventional treatment-refractory arrhythmias. The median age of the population was $56 \pm 16$ years, $67 \%$ were males. Five of the patients $(83 \%)$ had a history of hypertensive or ischemic cardiomyopathy and associated heart insufficiency; two female patients presented a congenital LQTS with associated arrhythmia (Table 1).

Regarding the initial clinical presentation, two of the cases referred dyspnea and palpitations as the first symptoms, three initiated with syncopal episodes, and one with chest pain. All the patients were initially treated with beta-blockers; five had an ICD implanted and underwent catheter ablation without symptomatic improvement. The patients with a history of LQTS had received pharmacological therapy before. Four of the patients were diagnosed with electrical storm, indicating the need for a VAT-LCSD; one of the patients had an episode of ventricular tachycardia associated with unstable angina. The patients with LQTS presented with polymorphic ventricular tachycardia unresponsive to beta-blocker management (portal vein thrombosis [PVT]).

The median hospitalization length was 7.5 days (interquartile range 6-16). Follow-up was conducted for 24; three cases a recurrence episode; two of them had an episode of slow ventricular tachycardia without severe symptoms, and the third experienced an episode of ventricular fibrillation treated by the ICD.

\section{Discussion}

Moss and McDonald adventured in the first descriptions of LCSD to prevent arrhythmias and sudden

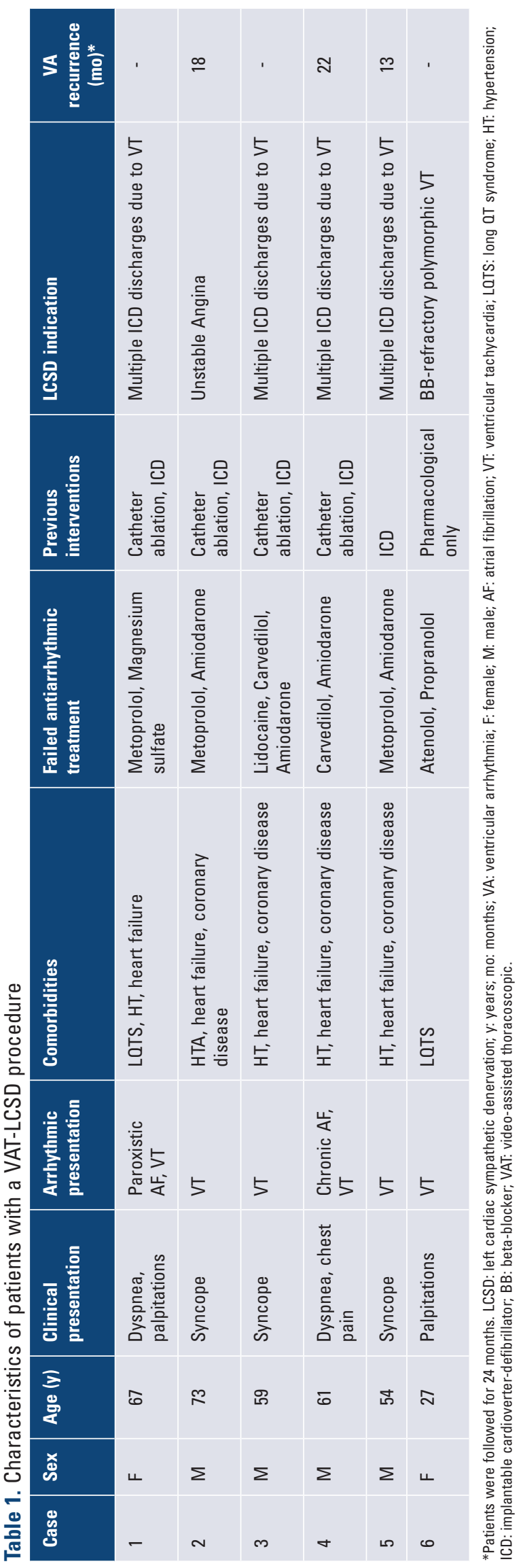


death in patients with LQTS more than 45 years ago ${ }^{7}$, but the implementation of a VAT was first reported in the year 2000, and the first series of cases was published in $2009^{8}$. Since then, it has a Class I recommendation for patients with refractory arrhythmias secondary to tissue scars in structural heart disease or LQTS and a Class IIB in cases of $\mathrm{PVT}^{9}$. In the past few years, some authors have extended the indication to patients requiring ICD implantation, as a complementary therapy in high-risk cases. Nevertheless, beta-blockers are still the first line of treatment for these conditions, although their efficiency is not homogeneous in every phenotype, dosing is challenging due to the variability of adverse effects in the general population, and they do not eliminate the risk of sudden death associated with these conditions ${ }^{10}$. Catheter ablation has also been recommended as the first line of treatment for patients with ventricular tachyarrhythmia storm when indicated it should be conducted in the first $48 \mathrm{~h}$ of hospital admission ${ }^{11}$. In our series, four patients with no absolute or relative contraindications for the procedure were treated with ablation therapy but did not achieve remission from the VA. The other two patients were refractory to other therapies. All the patients in our series received first-line treatment before proceeding to a VAT-LCSD. At present, there are no studies that are able to compare the efficacy of ablation therapy with sympathectomy, probably since ablation therapy is usually performed before VATLCSD in the management of these patients. LCSD has been suggested for patients with conditions refractory to catheter ablation; it has been stated that sympathetic modulation may be helpful for patients with multiple diseases with VA refractory to catheter ablation ${ }^{12}$.

Two of the patients in our series presented LQTS with associated PVT unresponsive to beta-blocker management. LCSD can disrupt the release of catecholamines in the ventricles, increasing the threshold for the onset of a $V A^{9}$. Besides the antifibrillatory effect of LCSD, a decrease in the QTC has been observed in the previous studies, but this effect has not been systematically confirmed ${ }^{13}$. In patients with primary VA such as congenital LQTS, failure to respond with beta-blockers should be considered an indication for VAT-LCSD as a treatment option. Although VAT-LCSD has strong evidence in the management of LQTS and PVT, recent studies have demonstrated a significant decrease in the number of cardiac events in patients with channelopathies and cardiomyopathies different from LQTS, with this procedure ${ }^{10}$.
The most common presentation of patients with cardiac arrhythmias in our series was ischemic and hypertensive cardiomyopathy with associated cardiac insufficiency. LCSD has been considered in previous literature as a substrate-independent antifibrillatory management alternative for some patients with arrhythmias stemming from other substrates besides LQTS $^{14}$. In an animal model of post-infarction sudden death, the VAT-LCSD procedure showed a significant decrease of ischemic ventricular fibrillation ${ }^{15}$. In humans, a study of cases with electrical storm due to ischemic and non-ischemic cardiomyopathy with no response to the first-line therapies showed a significant reduction in recurrent VA after $\operatorname{LCSD}^{16}$. Another study of 144 patients with myocardial infarction complicated by VA demonstrated a significant reduction in the incidence of sudden death with the procedure ${ }^{10}$. Reductions of up to $60 \%$ of arrhythmic episodes in patients with cardiomyopathy and refractory VA have also been reported ${ }^{17}$.

The primary indication for VAT-LCSD in our series was electrical storm in patients with an ICD with multiple shocks. Repeated ICD discharges have been linked with increased mortality and a reduction in life quality ${ }^{18}$. Both bilateral and LCSD have shown to attenuate the burden of ICD discharges in a small population in the acute setting. Reductions of up to $90 \%$ of the ICD shock burden have been reported in a larger population of patients with non-ischemic cardiomyopathy who were refractory to ablation and pharmacological therapy, in the long-term follow-up ${ }^{17}$.

From the data that we recollected, VAT-LCSD is not inferior to the open approach in term of efficacy. Reductions in the complications rate, hospital stay, and pleural drainage time have been shown with the VAT approach ${ }^{19}$. However, complications have been reported in patients who were submitted to VAT-LCSD such as unilateral facial erythema, facial dryness, contralateral hyperhidrosis, permanent blepharoptosis, and differential temperature sensation in the hands. These complications occur in $<10 \%$ of the patients ${ }^{20}$; in our series, none of these events were reported even though an active search was executed. Close follow-up revealed no signs of patients at risk for these complications in the future.

\section{Conclusions}

In general terms, VAT-LCSD is a valid treatment option for patients with ventricular tachyarrhythmias that prove to be challenging to treat with pharmacological and ablation therapies and for patients with repeated 
ICD discharges. This minimally invasive surgical procedure should be considered for patients with refractory VA in structural heart disease and congenital LQTS.

\section{Conflicts of interest}

None declared.

\section{Funding}

None.

\section{Ethical disclosures}

Protection of human and animal subjects. The authors declare that no experiments were performed on humans or animals for this study.

Confidentiality of data. The authors declare that they have followed the protocols of their work center on the publication of patient data.

Right to privacy and informed consent. The authors declare that no patient data appear in this article.

\section{References}

1. Khairy $P$. Ventricular arrhythmias and sudden cardiac death in adults with congenital heart disease. Heart. 2016;102:1703-9.

2. Tomaselli GF, Zipes DP. What causes sudden death in heart failure? Circ Res. 2004;95:754-63.

3. Goldenberg I, Moss AJ. Long QT syndrome. J Am Coll Cardiol. 2008;51:2291-300.

4. Pedersen CT, Kay GN, Kalman J, Borggrefe M, Della-Bella P, Dickfeld T, et al. EHRA/HRS/APHRS expert consensus on ventricular arrhythmias. Heart Rhythm. 2014;11:e166-96.

5. Yanowitz F, Preston JB, Abildskov JA. Functional distribution of right and left stellate innervation to the ventricles. Production of neurogenic electrocardiographic changes by unilateral alteration of sympathetic tone. Circ Res. 1966;18:416-28.
6. Cao JM, Fishbein MC, Han JB, Lai WW, Lai AC, Wu TJ, et al. Relationship between regional cardiac hyperinnervation and ventricular arrhythmia. Circulation. 2000;101:1960-9.

7. Moss AJ, McDonald J. Unilateral cervicothoracic sympathetic ganglionectomy for the treatment of long QT interval syndrome. N Engl J Med. 1971;285:903-4

8. Li J, Wang L, Wang J. Video-assisted thoracoscopic sympathectomy for congenital long QT syndromes. Pacing Clin Electrophysiol. 2003; 26:870-3.

9. Wilde AA, Bhuiyan ZA, Crotti L, Facchini M, De Ferrari GM, Paul T, et al. Left cardiac sympathetic denervation for catecholaminergic polymorphic ventricular tachycardia. N Engl J Med. 2008;358:2024-9.

10. Schwartz PJ. Cardiac sympathetic denervation to prevent life-threatening arrhythmias. Nat Rev Cardiol. 2014;11:346-53.

11. Priori SG, Blomström-Lundqvist C, Mazzanti A, Blom N, Borggrefe $M$ Camm J, et al. 2015 ESC guidelines for the management of patients with ventricular arrhythmias and the prevention of sudden cardiac death: the task force for the management of patients with ventricular arrhythmias and the prevention of sudden cardiac death of the European society of cardiology (ESC). Endorsed by: association for European paediatric and congenital cardiology (AEPC). Eur Heart J. 2015;36:2793-867.

12. Richardson T, Lugo R, Saavedra P, Crossley G, Clair W, Shen S, et al. Cardiac sympathectomy for the management of ventricular arrhythmias refractory to catheter ablation. Heart Rhythm. 2018;15:56-62.

13. Collura CA, Johnson JN, Moir C, Ackerman MJ. Left cardiac sympathetic denervation for the treatment of long QT syndrome and catecholaminergic polymorphic ventricular tachycardia using video-assisted thoracic surgery. Heart Rhythm. 2009;6:752-9.

14. Coleman MA, Bos JM, Johnson JN, Owen HJ, Deschamps C, Moir C et al. Videoscopic left cardiac sympathetic denervation for patients with recurrent ventricular fibrillation/malignant ventricular arrhythmia syndromes besides congenital long-QT syndrome. Circ Arrhythm Electrophysiol. 2012;5:782-8.

15. Schwartz PJ, Billman GE, Stone HL. Autonomic mechanisms in ventricular fibrillation induced by myocardial ischemia during exercise in dogs with healed myocardial infarction. An experimental preparation for sudden cardiac death. Circulation. 1984;69:790-800.

16. Shah SR, Keshri A, Patadia S, Marak RS, Behari S. Invasive aspergillosis of anterior skull base in the immunocompetent host: outcomes with a combined treatment modality-an institutional experience. J Neurol Surg B Skull Base. 2017;78:89-95.

17. Vaseghi M, Gima J, Kanaan C, Ajijola OA, Marmureanu A, Mahajan A, et al. Cardiac sympathetic denervation in patients with refractory ventricular arrhythmias or electrical storm: intermediate and long-term follow-up. Heart Rhythm. 2014;11:360-6.

18. Poole JE, Johnson GW, Hellkamp AS, Anderson J, Callans DJ, Raitt MH, et al. Prognostic importance of defibrillator shocks in patients with heart failure. N Engl J Med. 2008;359:1009-17.

19. Weatherford DA, Stephenson JE, Taylor SM, Blackhurst D. Thoracoscopy versus thoracotomy: indications and advantages. Am Surg. 1995;61:83-6.

20. Waddell-Smith KE, Ertresvaag KN, Li J, Chaudhuri K, Crawford JR, Hamill JK, et al. Physical and psychological consequences of left cardiac sympathetic denervation in long-QT syndrome and catecholaminergic polymorphic ventricular tachycardia. Circ Arrhythm Electrophysiol. 2015; 8:1151-8 